Review

\title{
Antiviral agents against flavivirus protease: prospect and fu- ture direction
}

\author{
Subodh K Samrat ${ }^{1}$, Jimin $\mathrm{Xu}^{2}$, Zhong $\mathrm{Li}^{1}$, Jia $\mathrm{Zhou}^{2}$ and Hongmin $\mathrm{Li}^{1,3}$ \\ 1 Department of Pharmacology and Toxicology, College of Pharmacy, the University of Arizona, 1703 E Ma- \\ bel St, Tucson, Arizona 85721-0207, United States of America \\ 2 Chemical Biology Program, Department of Pharmacology and Toxicology, University of Texas Medical \\ Branch, Galveston, Texas 77555, United States of America \\ 3 BIO5 Institute, The University of Arizona, Tucson, Tucson, Arizona 85721, United States of America \\ * : Correspondence: hli1@pharmacy.arizona.edu, Tel: 520-621-5728
}

\begin{abstract}
Flaviviruses cause a significant amount of mortality and morbidity, especially in the area where they are endemic. A recent example is the outbreak of Zika virus though out the world. Development of antiviral drugs against different viral targets is as important as development of vaccine. During viral replication, the flavivirus genome is translated as a single polyprotein precursor, which must be cleaved into individual proteins by a complex of the viral protease, NS3, and its cofactor, NS2B. Flavivirus protease is the most attractive target for development of therapeutic antivirals because it is essential for processing of viral polyprotein precursor and generation of functional viral proteins. In this review, we have summarized recent development in drug discovery targeting NS3-NS2B protease of flaviviruses, especially Zika, dengue and West Nile virus.
\end{abstract}

Keywords: Flavivirus; NS2B-NS3; ZIKA Virus; Dengue Virus; West Nile Virus; Inhibitors;

\section{Introduction}

Flavivirus genus of the Flaviviridae family includes more than 70 related arthropodborne viruses [1-4]. The most common and representative members are the dengue virus (DENV) with four closely related but antigenically distinct serotypes (DENV-1, DENV-2, DENV-3, and DENV-4), Zika (ZIKV), West Nile (WNV), Yellow Fever (YFV), Japaneseencephalitis (JEV), tick-borne-encephalitis (TBEV), and Usutu viruses [5-7]. These are the causative agents for viral hemorrhagic fever and encephalitis in human beings.

Flaviviruses are transmitted to susceptible hosts by infected arthropod vectors [8-11]. Many flaviviruses are restricted to a particular region. An occasional spill of viruses is frequently occurring, which is a significant challenge for international health care. For examples, WNV jumped from the Middle East into the Americas [12,13]; and ZIKV spread from Africa to Southeast Asia, the islands of Polynesia, and later to Brazil in 2015-2016, causing an epidemic $[3,14,15]$.

There is no approved antiviral therapeutic or vaccine available to combat most flavivirus infections, except for YFV, DENV, JEV, Kyasanur forest disease virus (KFDV), and TBEV [11]. In the case of DENV, vaccine design and development have been hampered because the incomplete vaccine immunity against all four serotypes may lead to an antibody-dependent enhancement in the setting of subsequent natural infection [11,16]. As a result, the goal is to develop a vaccine that simultaneously elicits a balanced tetravalent neutralizing response against all four DENV serotypes. In 2019, the United States Food and Drug Administration (FDA) approved the live-attenuated, tetravalent vaccine, Dengvaxia (from Sanofi Pasteur), but only for individuals between 9-16 years of age who have laboratory-confirmed prior DENV infection and are living in endemic areas $[16,17]$. 
These challenges increase the demand to develop therapeutics and vaccines that targets different flaviviruses.

The development of antiviral therapeutics will enable new approaches for the management of flavivirus outbreaks due to their potential for use as treatment and prophylaxis $[18,19]$. In this review, we describe strategies and examples of current efforts to identify potential inhibitors against flavivirus NS3 protease activities that can be developed as therapeutic agents to combat flavivirus infections.

\section{Flavivirus genome organization}

Flavivirus genome consists of a positive-sense single-stranded RNA which is $\sim 11 \mathrm{~kb}$ in length, consisting of a $5^{\prime}$ untranslated region (UTR), a single long open reading frame (ORF), and a 3' UTR [3,4,20,21]. It is capped like cellular mRNAs, but not polyadenylated. The single ORF encodes a polyprotein precursor (PP) that is further processed with the help of host and viral proteases. The flavivirus protease, which works with host proteases to cleave the viral PP, is a highly conserved enzyme essential for virus replication. The viral PP is processed to three structural proteins (Capsid, pr-Membrane, and Envelope) and seven non-structural (NS) proteins (NS1, NS2A, NS2B, NS3, NS4A, NS4B, and NS5) $[4,21]$. Three structural proteins form the virus coat, whereas seven NS proteins are part of the membrane-bound replication complex. Among these NS proteins, only NS3 and NS5 bear enzymatic functions [19,22,23] (Fig 1).

\section{Flavivirus protease}

NS3 is a protein with multiple functions, including protease, helicase, and triphosphatase activities [24,25]. The NS3 N-terminal domain (amino acids (aa) 1-180) is a trypsin-like serine protease with a classic catalytic triad (Ser135-His51-Asp75) [3,26]. It requires a small hydrophilic proportion of NS2B as a co-factor for activating the protease enzymatic function [27-29]. The NS3 C-terminus domain (aa 180-618) is a superfamily 2ATPase/helicase that binds to the $3^{\prime}$ end of transient dsRNA and unwinds it in $3^{\prime} \rightarrow 5^{\prime}$ direction [30]. In addition, the C-terminal domain of NS3 also has RNA $5^{\prime}$-triphosphatase activity for viral RNA 5'-capping [23,31].
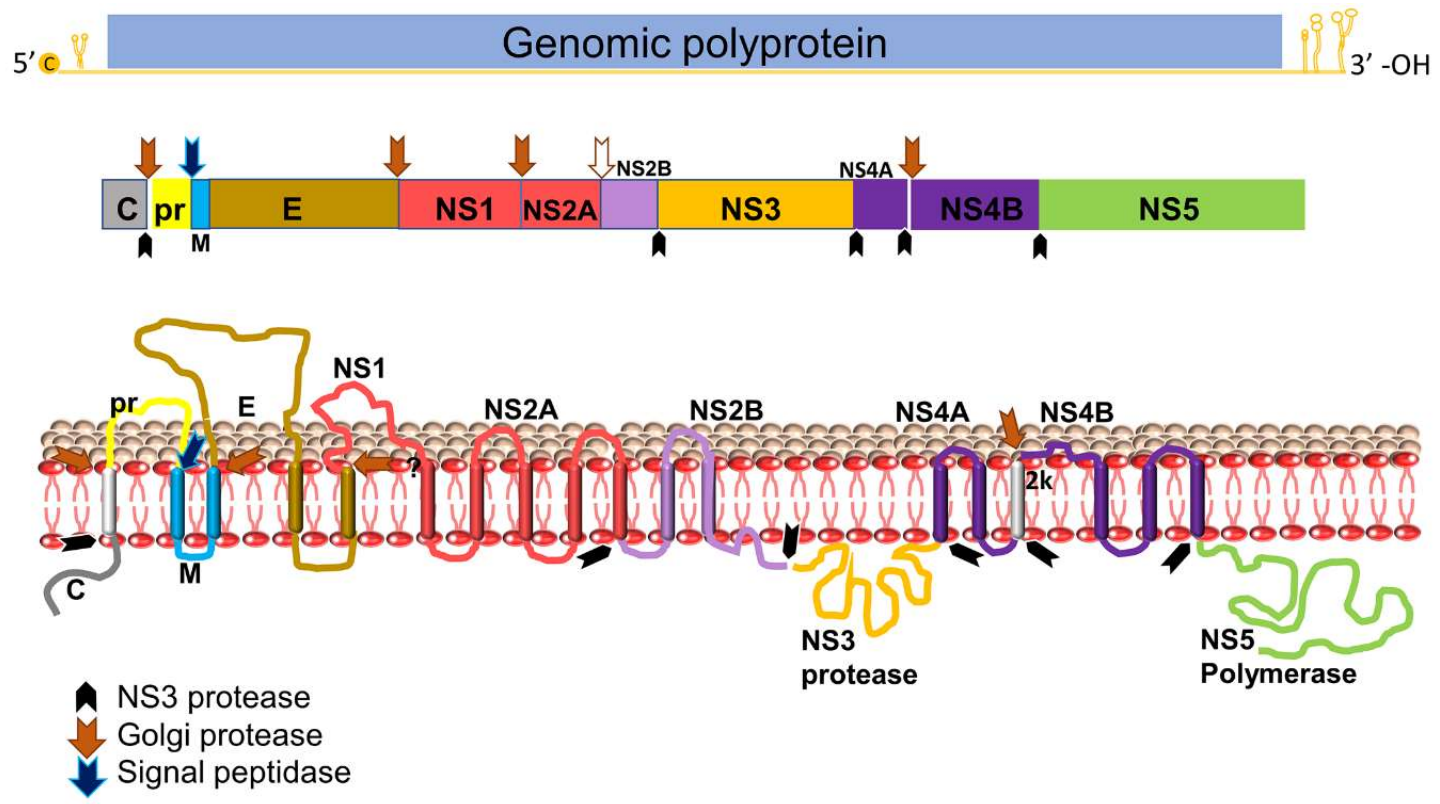

Figure 1. Schematic diagram of flavivirus polyprotein organization, processing, and predicted membrane topology of mature protein. Top, the representative flavivirus genome. c, RNA cap. Middle, linear organization of the structural and nonstructural proteins within the polyprotein. Black 
arrows denote cleavage by the viral NS2B-NS3 protease complex, whereas the brown arrows indicate cleavage by the Golgi protease and blue arrow denotes cleavage by signal peptidase. Bottom, putative membrane topology of the polyprotein predicted from biochemical and cellular analyses, which is further processed by host and viral proteases (indicated by arrows).

NS2B is an integral membrane protein of $14 \mathrm{kDa}$ with three domains: two transmembrane segments located at the $\mathrm{N}$ and $\mathrm{C}$ termini and a central region of 47 amino acids (spanning aa 49-96) that interacts with the NS3 protease as a co-factor (Fig 1) [29,32]. It has been reported that flavivirus NS3 protein is neither soluble nor catalytically active as a protease in vitro, without providing NS2B either in cis [33-35] or in trans [36-40]. Proteases among flaviviruses have significant similarity on both structural and sequence levels [41].

The flavivirus NS2B-NS3 protease is one of the most promising validated targets for developing a pan flavivirus treatment which is evidenced by the clinical availability of ten HIV-1 protease inhibitors (PIs) [42-44] and the two HCV Protease inhibitors [45-47]. Thus, it is plausible that a protease inhibitor for flaviviruses will be efficacious in the clinic. However, experience with both HIV-1 and HCV indicates that there are certain drawbacks associated with PIs, which are important considerations in developing a flavivirus protease inhibitor. Because both HIV and HCV cause chronic infections, PI drug-resistant viral strains were rapidly observed [48]. In contrast, most flaviviruses cause acute infections, drug resistance may be less of a concern.

Most attempts to develop flavivirus protease inhibitors have focused on the NS3 active site with limited success possibly due to flat and featureless active site and requirement of charged substrate to bind with P1 and P2 sites. Moreover, many of the active site inhibitors are only effective in biochemical assays but show poor bioavailability in vivo [48].

\section{Structural insight of NS2B-NS3 protease}

Structural study of NS2B-NS3 led to better screening assays to identify protease inhibitors $[49,50]$. The NS2B and NS3 protein complex adopts two different conformations [15]. In the absence of substrate or active-site inhibitor, the NS2B C-terminal portion adopts an "open" inactive conformation (Fig 2A) [15,51]. However, in the presence of inhibitor or substrate binding to the NS3 active site, the C-terminal portion of NS2B "wraps around" the NS3 core, closing the NS3 active site with the so-called active "closed" conformation [52] (Fig 2B and 2C). NS2B conformational changes are required for NS3 function; mutations that abrogate NS2B binding greatly reduce the proteolytic activity of the complex $[15,53,54]$.
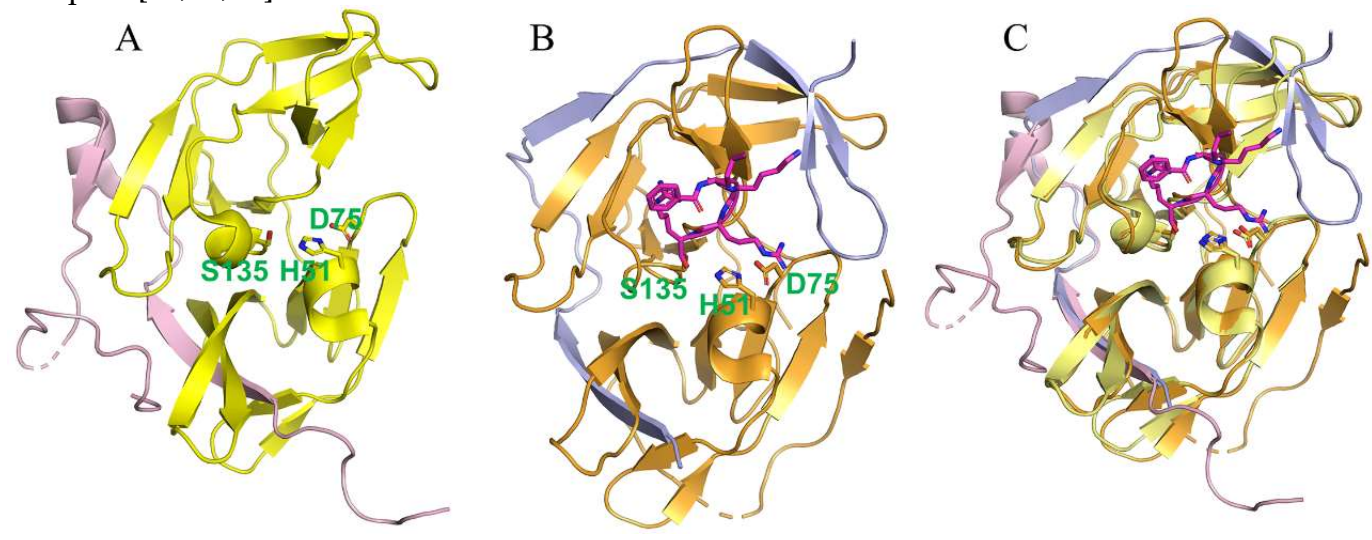

Figure 2. Crystal structures of the dengue NS2B-NS3 protease. (A) The open (inactive) conformation (PDB ID of 2FOM) in the unbound state. The NS2B cofactor is colored in purple and NS3 protease in yellow. (B) The closed (active) conformation (PDB ID of 3U1I) in complex with a substrate peptide analog (magenta sticks). The NS2B cofactor is colored in blue and NS3 protease in orange. (C) 
Superimposed structure of inactive and active conformation. The catalytic triad His51-Asp75-Ser135 is displayed in stick representation.

\section{NS2B-NS3 protease inhibitors:}

The functional significance of NS2B-NS3 protease makes it an important target for drug development against flaviviruses. The structural and functional similarity among the proteases of different flaviviruses further indicates its significance. Several studies have reported the development of inhibitors of NS2B-NS3 protease that target either the active site or allosteric/orthosteric site of the enzyme. These inhibitors may be referred to competitive and non-competitive inhibitors, respectively. In this review, we have reviewed the inhibitors against the NS2B-NS3 protease of ZIKV, DENV, and WNV reported in literatures between 2015 and 2021.

\subsection{Competitive inhibitors}

The competitive inhibitor drugs are known to interact with NS2B-NS3 protease at the active site and inhibit the enzyme activity. Several drugs have been identified that work as competitive inhibitors against flavivirus NS2B-NS3 protease, as shown in Fig 3 and listed in Table 1.

Table 1. Competitive inhibitors of flavivirus NS2B-NS3 protease.

\begin{tabular}{|c|c|c|c|c|c|}
\hline Number (Name) of compound & $\begin{array}{l}\text { Targeted } \\
\text { virus }\end{array}$ & $\operatorname{IC}_{50}\left(\right.$ or $\left.\mathrm{K}_{\mathrm{i}}\right)(\boldsymbol{\mu} \mathrm{M})$ & $\mathrm{EC}_{50}(\mu \mathrm{M})$ & In vivo & Reference \\
\hline 1 (Novobiocin) & Zika & $14.2 \pm 1.1$ & 42.63 & Yes & [55] \\
\hline 2 (Asunaprevir) & Zika & 6.0 & 4.7 & & {$[56]$} \\
\hline 3 (Simeprevir) & Zika & 2.6 & 0.4 & & {$[56]$} \\
\hline 4 (carbazole-based amidines) & Zika & 0.52 & 1.25 & & {$[57]$} \\
\hline $5(\mathrm{MK}-591)$ & Zika & 3.0 & 3.1 & & [58] \\
\hline $6(\mathrm{JNJ}-40418677)$ & Zika & 3.9 & 3.2 & & [58] \\
\hline 7 (4-CF3-benzyl ether) & $\begin{array}{l}\text { TBEV } \\
\text { Zika }\end{array}$ & $\begin{array}{l}0.92 \\
1.64 \\
\end{array}$ & & & [59] \\
\hline 8 & $\begin{array}{l}\text { Zika } \\
\text { TBEV } \\
\text { DENV } \\
\text { WNV }\end{array}$ & $\begin{array}{c}0.25 \\
0.97 \\
0.05 \\
0.018\end{array}$ & $\begin{array}{c}3.4 \\
15.5\end{array}$ & & {$[60]$} \\
\hline 9 & $\begin{array}{l}\text { Zika } \\
\text { TBEV }\end{array}$ & $\begin{array}{l}0.94 \\
3.72 \\
\end{array}$ & & & [60] \\
\hline 10 (Policresulen) & DENV-2 & $0.48 \mu \mathrm{g} / \mathrm{mL}$ & $4.99 \mu \mathrm{g} / \mathrm{mL}$ & & {$[62]$} \\
\hline 11 & DENV-2 & 0.95 & & & {$[61,63]$} \\
\hline 12 & DENV & 1.1 & 2.0 & & {$[63]$} \\
\hline 13 PCRARIYGGCA & DENV-3 & $\mathrm{Ki}=2.9$ & & & [65] \\
\hline $\mathbf{1 4}(\mathrm{C} 30 \mathrm{H} 25 \mathrm{NO})$ & DENV-2 & 17.46 & 14.9 & & [66] \\
\hline $\mathbf{1 5}(\mathrm{C} 34 \mathrm{H} 23 \mathrm{NO}$ S 2$)$ & DENV-2 & 9.09 & 11.8 & & [66] \\
\hline $\begin{array}{c}16 \text { (Peptide-hybrid inhibitors } \\
\text { based on 2,4-thiazolidinedione } \\
\text { scaffold) } \\
\end{array}$ & $\begin{array}{l}\text { WNV } \\
\text { DENV }\end{array}$ & $\begin{array}{l}0.75 \\
1.05\end{array}$ & & & [67] \\
\hline 17 ( $\alpha$-aminoalkylphosphonates) & DENV-2 & $\mathrm{Ki}=0.4$ & & & [68] \\
\hline $\begin{array}{c}18 \text { (Theaflavin-3,3'-digallate } \\
\text { (ZP10) }\end{array}$ & Zika & 7.65 & 3 & & [69] \\
\hline
\end{tabular}

\subsubsection{Repurposed inhibitors}

Yuan et. al., performed an in silco screening of more than 8,000 drugs, followed by biochemical and cellular assay. The FDA-approved drug 1 (Novobiocin) was found as the most promising ZIKV NS2B-NS3 protease inhibitor [55]. Animal studies suggest that Novobiocin treatment reduces viral load in blood and major organs of mice and increases the mouse survival rates [55]. 
Using structure-based pharmacophore anchor approach, Pathak et al. showed that the FDA-approved drugs, compounds 2 (Asunaprevir) and 3 (Simeprevir) inhibited the ZIKV protease with IC50 values of $6.0 \mu \mathrm{M}$ and $2.6 \mu \mathrm{M}$, respectively [56]. These molecules also showed anti-ZIKV activity with $\mathrm{EC}_{50}$ values of $4.7 \mu \mathrm{M}$ and $0.4 \mu \mathrm{M}$, respectively [56]. However, these molecules need further validation in animal model for its anti ZIKV activity.

\subsubsection{Synthetic inhibitors}

Initial efforts were made to develop peptides-based protease inhibitor with or without serine trap. However, peptides are in general unstable in vivo and mostly non-permeable to cross cell membranes, so focus now has changed to develop small molecule against flavivirus protease [57].

Rassias et al synthesized a series of novel N-substituted carbazole-based amidines as ZIKV protease inhibitors, and compound 4 (carbazole derivative) demonstrated its in vitro biochemical and cell-based inhibitory profiles against ZIKV with an IC 50 of $0.52 \mu \mathrm{M}$ and $\mathrm{EC}_{50}$ of $1.25 \mu \mathrm{M}$ [57]. 


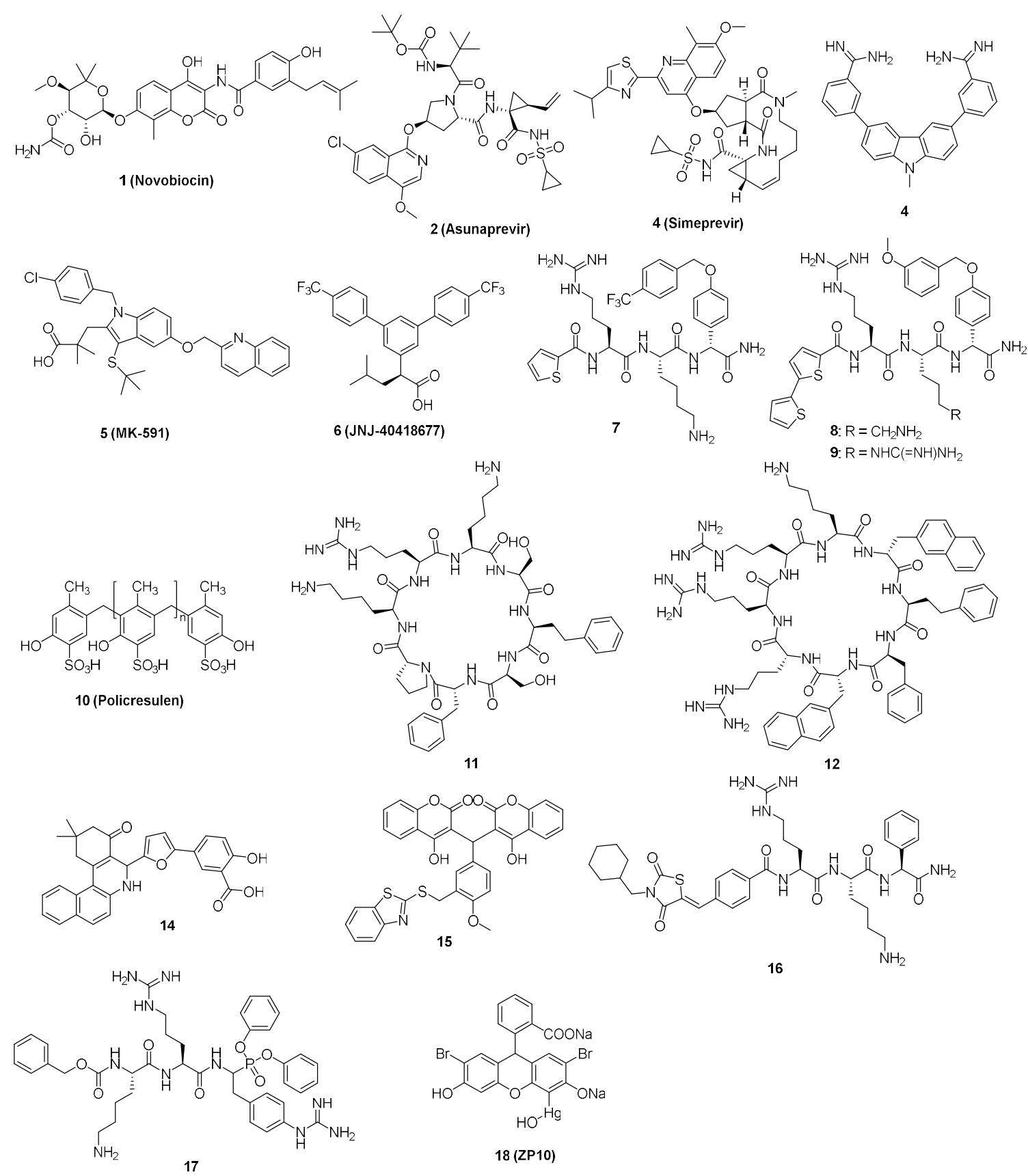

Figure 3. The chemical structures of compounds 1-18 as competitive inhibitors of flavivirus NS2BNS3 protease.

Using quantitative high throughput screenings (qHTS) for small-molecule protease inhibitors, Abrams et al [58] found that compounds 5 (MK-591) and 6 (JNJ-40418677) showed antiviral effects primarily through inhibition of the Zika viral protease with IC 50 values of $3.0 \mu \mathrm{M}$ and $3.9 \mu \mathrm{M}$, respectively. Moreover, compounds 5 and 6 showed the ability to inhibit ZIKV in human neuronal stem cells using a ZIKV isolate from the 2013 French Polynesian outbreak with EC50 values of $3.1 \mu \mathrm{M}$ and $3.2 \mu \mathrm{M}$ respectively [58].

In another study using different in silico methods, compound 7 (4-CF3-benzyl ether), a pan inhibitor of DENV, WNV and ZIKV proteases, was found as an active inhibitor against the TBEV protease [59]. In vitro protease assay confirmed that compound 7 
inhibited the TBEV protease with an $\mathrm{IC}_{50}$ value of $0.92 \mathrm{uM}$. Another two analogues of compound 7 named in our manuscript as compounds 8 and 9 show strong TBEV protease inhibition with $\mathrm{IC}_{50}$ values of $0.97 \mu \mathrm{M}$ and $3.72 \mu \mathrm{M}$, respectively [60]. The antiviral efficacy of these compounds remains elusive.

Interestingly the compound 8 has also been described as an inhibitor of the NS2BNS3 proteases of DENV and WNV by Behnam et al [61]. The compound 8 showed IC 50 values of $50 \mathrm{nM}$ and $18 \mathrm{nM}$ against the DENV and WNV proteases, respectively. The inhibitor also displayed significant reduction of DENV and WNV titers in cell-based assays with $\mathrm{EC}_{50}$ of $3.4 \mu \mathrm{M}$ and $15.5 \mu \mathrm{M}$ respectively [61].

Several synthetic competitive inhibitors have been identified that target the active site of the DENV NS2B-NS3 protease and affect the cleavage of substrate polyprotein. Compound 10 (Policresulen) is one of the compounds predicted to interact with Gln106 and Arg133 of the DENV-2 NS2B-NS3 protease and affects its stability, leading to inhibition of its protease activity and virus replication at an $\mathrm{IC}_{50}$ of $0.48 \mu \mathrm{g} / \mathrm{mL}$ and an $\mathrm{EC}_{50}$ of $4.99 \mu \mathrm{g} / \mathrm{mL}$, respectively [62].

Another approach for inhibiting the protease activity is to generate synthetic cyclic peptides as competitive inhibitors mimicking the substrate of NS2B-NS3 protease. Takagi et al. synthesized an array of cyclic peptides, showing that proper positioning of arginine and aromatic residues in these cyclic peptides enhanced the DENV-specific antiviral activity at an $\mathrm{IC}_{50}$ of $0.95 \mu \mathrm{M}$ for the most potent compound 11 [63]. Unfortunately, this compound does not have antiviral activity. Incorporation of L-2-naphthylalanine and adjust positions of arginine led to discovery of compound 12, which showed significant antiDENV activity with EC 50 of $2.0 \mathrm{uM}$, although with slightly reduced protease inhibition of IC 50 of $1.1 \mathrm{uM}$ [63].

In a recent study, Lin et al explored cyclic peptides based on aprotinin, a pan-serine protease inhibitor composed of a monomeric globular polypeptide of 58 amino acids $[64,65]$. Because targeting the P side of the enzyme can affect the human serine protease activity, the binding loop of aprotinin was engineered to identify the optimal hydrophobic amino acids for each of the $\mathrm{P}^{\prime}$ positions. The cyclic peptides (CPs) to target both $\mathrm{P}$ and $\mathrm{P}^{\prime}$ sites of the DENV protease active-site pocket were designed to optimize their sequence and length. The best binding cyclic peptide 13 (CP7) has a $K_{i}$ value of $2.9 \mu \mathrm{M}$ against the DENV-3 protease [65]. However, the antiviral potency of these cyclic peptides was not evaluated.

Several non-peptide molecules with inhibitory effect on the DENV NS2B-NS3 protease have been identified and tested against DENV. Two of the tested compounds viz. 14 (C30H25NO5 (CID: 54692801)) and 15 (C34H23NO7S2 (CID: 54715399)) were shown to have significant inhibitory effect on the NS2B-NS3 protease as was observed in the fluorometric enzyme assay using synthetic peptide Boc-Gly-Arg-Arg-AMC as a fluorescent substrate with IC50 of $17.46 \mu \mathrm{M}$ and $9.09 \mu \mathrm{M}$, respectively [66]. Assessment of anti-DENV activity revealed that these compounds have moderate antiviral activity with EC50 values of $14.9 \mu \mathrm{M}$ and $11.8 \mu \mathrm{M}$, respectively [66].

WNV is another medically important flavivirus which need NS2B-NS3 protease for its replication. Several inhibitors have been designed till date to block the activity of viral protease. Bastos Lima et al. synthesized a group of novel reversible peptide-hybrid inhibitors based on compound 16 (2,4-thiazolidinedione scaffold) [67], with low micromolar inhibitory activities against the WNV and DENV proteases, although their antiviral efficacy was not investigated.

Recently, synthesis and application of $\alpha$-aminoalkyl phosphonates and their peptidyl derivatives as the WNV NS2B-NS3 protease inhibitors have been reported [68]. These compounds belong to a class of irreversible inhibitors that specifically and exclusively react with the active site serine residue, leading to formation of a slow hydrolyzing protease-inhibitor complex. The most potent compound 17 was observed to have a $K_{i}$ value of $0.4 \mu \mathrm{M}$ [68]. The antiviral efficacy of this compound remains elusive. 


\subsubsection{Natural compound inhibitors}

Several studies have shown that compounds derived from natural sources viz. plants or microorganisms can exhibit broad range medicinal properties. In a study using fluorescence-based screening assay it was shown that natural active compound 18 (theaflavin3,3'-digallate, ZP10), derived from black tea, acted as a potent ZIKV protease inhibitor with IC 50 value of $3 \mu \mathrm{M}$. ZP10 exhibited dose-dependent inhibitory effect on ZIKV replication $\left(\mathrm{EC}_{50}=7.65 \mu \mathrm{M}\right)$ [69]. Compound 18 directly was predicted to bind to several critical residues at the proteolytic cavity of the NS2B-NS3 protease and inhibited the polyprotein processing [69].

\subsection{Non-competitive inhibitors}

The non-competitive inhibitors are known to interact with NS2B-NS3 protease at a site other than the active site (allosteric or orthosteric site) and modulate the enzyme activity. Unlike the flat and featureless active site, the NS3 pockets holding the NS2B Nterminal residues (such as key contact residues L51, L53, V59, and W61, DENV-2 number) are deep and hydrophobic. Since the NS2B binding is essential for protease function, an alternative strategy to target the NS2B-NS3 interaction interface to inhibit the NS3 protease function orthosterically has been investigated $[15,70]$. The novel approach avoided the active site's featureless nature and the necessity for charged inhibitors at the active site. Several recently identified non-competitive inhibitors are discussed in this as also shown in Fig 4 and listed in Table 2.

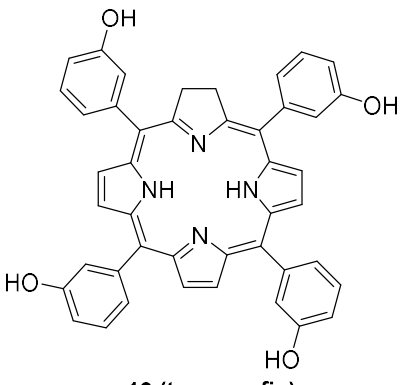

19 (temoporfin)

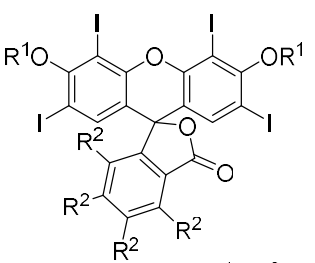

23 (Erythrosin $B$ ): $R^{1}=R^{2}=H$ 24 (JMX0902): $\mathrm{R}^{1}=\mathrm{Na}, \mathrm{R}^{2}=\mathrm{Cl}$

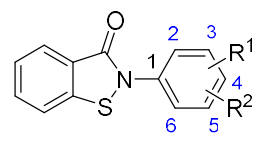

31: $\mathrm{R}^{1}, \mathrm{R}^{2}=2-\mathrm{Me}-4-\mathrm{NO}_{2}$ 32: $\mathrm{R}^{1}, \mathrm{R}^{2}=2-\mathrm{Cl}$ 33: $R^{1}, R^{2}=2,6-d i C l$

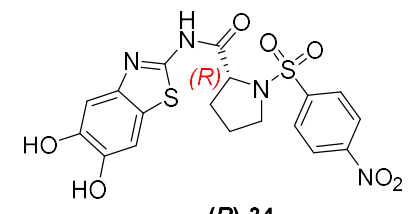

$(R)-34$<smiles>O=C(Nc1ccc([N+](=O)[O-])cc1Cl)c1cc(Cl)ccc1O</smiles>

20 (Niclosamide)<smiles>CC(=O)Oc1ccccc1C(=O)Nc1ncc([N+](=O)[O-])s1</smiles>

21 (Nitazoxanide)<smiles>CN(C)c1ccc2nc3ccc(=[N+](C)C)cc-3sc2c1</smiles>

22 (Methylene blue)<smiles>O=C(Nc1ccc([N+](=O)[O-])cc1Cl)c1cccc([N+](=O)[O-])c1O</smiles>

25 (JMX0207)

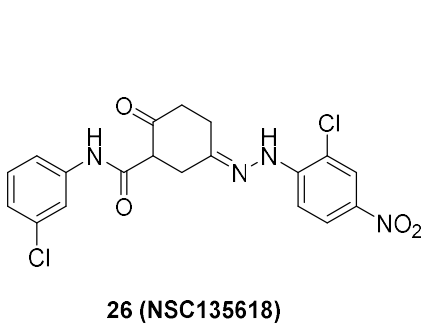<smiles></smiles>

28, $R^{1}=R^{2}=t-B u$

29: $\mathrm{R}^{1}=\mathrm{CH}_{2} \mathrm{NH}, \mathrm{R}^{2}=$ 30: $\mathrm{R}^{1}=\mathrm{CH}_{2} \mathrm{NH}_{2}, \mathrm{R}^{2}=$<smiles>Cc1ccc(S(=O)(=O)N2CCCCC2C(=O)Nc2nc3cc(O)c(O)cc3s2)cc1</smiles>

(R)-35

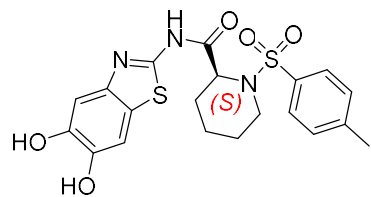

(S)-35
Figure 4. The chemical structures of compounds 19-35 as noncompetitive inhibitors of flavivirus NS2B-NS3 protease. 
Table 2. Noncompetitive inhibitors of flavivirus NS2B-NS3 protease.

\begin{tabular}{|c|c|c|c|c|c|}
\hline $\begin{array}{l}\text { Number (Name) of } \\
\text { compound }\end{array}$ & Targeted virus & $\mathrm{IC}_{50}(\mu \mathrm{M})$ & $\mathrm{EC}_{50}(\mu \mathrm{M})$ & In vivo & Reference \\
\hline \multirow{5}{*}{19 (Temoporfin) } & Zika & \multirow{5}{*}{$1.1 \pm 0.1$} & 0.024 & \multirow{5}{*}{ Yes } & \multirow{5}{*}[70]{} \\
\hline & DENV-2 & & 0.020 & & \\
\hline & WNV & & 0.010 & & \\
\hline & JEV & & 0.011 & & \\
\hline & YFV & & 0.006 & & \\
\hline \multirow{5}{*}{20 (Niclosamide) } & Zika & & 0.48 & & \multirow{5}{*}[70]{} \\
\hline & DENV-2 & & 0.55 & & \\
\hline & WNV & $12.3 \pm 0.6$ & 0.54 & & \\
\hline & JEV & & 1.02 & & \\
\hline & YFV & & 0.84 & & \\
\hline \multirow{2}{*}{21 (Nitazoxanide) } & Zika & \multirow{2}{*}{$15.9 \pm 0.9$} & 1.48 & & \multirow{2}{*}[70]{} \\
\hline & JEV & & 0.39 & & \\
\hline \multirow{2}{*}{22 (methylene blue) } & DENV-2 & \multirow[t]{2}{*}{8.9} & 0.36 & \multirow[b]{2}{*}{ Yes } & {$[71]$} \\
\hline & ZIKV & & $0.087-0.2$ & & [71] \\
\hline \multirow{5}{*}{23 (Erythrosin B) } & ZIKV & & 0.62 & \multirow{5}{*}{ Yes } & \multirow{5}{*}[72]{} \\
\hline & DENV-2 & & 1.2 & & \\
\hline & WNV & $\begin{array}{l}1.7 \\
1.9\end{array}$ & 0.66 & & \\
\hline & JEV & & 0.35 & & \\
\hline & YFV & & 0.57 & & \\
\hline 24 (JMX0902) & Zika & 2.6 & 0.3 & & [73] \\
\hline \multirow{2}{*}{25 (JMX0207) } & ZIKV & & 0.3 & \multirow{2}{*}{ Yes } & \multirow{2}{*}[74]{} \\
\hline & DENV & 8.2 & 0.31 & & \\
\hline \multirow{4}{*}{26 (NSC135618) } & DENV-2 & & 0.81 & & \multirow{4}{*}[15]{} \\
\hline & Zika & & 1.0 & & \\
\hline & WNV & 1.8 & 1.27 & & \\
\hline & YFV & & 0.28 & & \\
\hline 27 & Zika & 21.7 & & & 44 \\
\hline 28 & Zika & 3.1 & & & 44 \\
\hline \multirow{4}{*}{29} & ZIKV & $0.20 \pm 0.01$ & \multirow{4}{*}{$\mathrm{EC}_{68} 0.3$ or 0.6} & \multirow{4}{*}{ Yes } & \multirow{4}{*}[75,76]{} \\
\hline & DENV-2 & $0.59 \pm 0.02$ & & & \\
\hline & DENV-3 & $0.52 \pm 0.06$ & & & \\
\hline & WNV & $0.78 \pm 0.02$ & & & \\
\hline \multirow{3}{*}{30} & Zika & 0.13 & & & \\
\hline & DENV-2 & 2.4 & $\mathrm{EC}_{68} 0.6$ & & [76] \\
\hline & WNV & 0.82 & & & \\
\hline 31 & DENV-2 & $2.56 \pm 1.03$ & $<30$ & & [77] \\
\hline 32 & DENV-2 & $2.01 \pm 0.98$ & $<30$ & & [77] \\
\hline 33 & DENV-2 & $5.28 \pm 1.89$ & $<30$ & & [77] \\
\hline$(R)-34$ & DENV-2 & 0.32 & $<3$ & & [78] \\
\hline$(R)-35$ & DENV-2 & 0.51 & & & [78] \\
\hline$(S)-35$ & DENV-2 & 0.58 & & & [78] \\
\hline
\end{tabular}

Li et al developed a split luciferase complementation (SLC)-based protein-protein interaction assay to monitor NS2B-NS3 interactions [70]. A total of 2,816 approved and investigational drugs were screened. Several orthosteric inhibitors capable of abolishing the NS2B-NS3 interactions were identified. Among these, 23 compounds were found to have an IC 50 value below $15 \mu \mathrm{M}$. Three of them, including compounds 19 (temoporfin), 20 (niclosamide), and 21 (nitazoxanide), could inhibit the viral NS2B-NS3 protease activity with an $\mathrm{IC}_{50}$ of $1.1 \pm 0.1,12.3 \pm 0.6,15.9 \pm 0.9 \mu \mathrm{M}$ and cytotoxicity $\mathrm{CC}_{50}$ of $40.7 \pm 0.7,4.8 \pm 1.0,77$ $\pm 7.2 \mu \mathrm{M}$ in A549 cells, respectively. These molecules are broad-spectrum antivirals against multiple representative flaviviruses with $\mathrm{EC}_{50}$ values in low micromolar to nanomolar range (Table 2). Temoporfin was further tested in animal model showing that it could inhibit viremia and protect $83 \%$ of mice from lethal challenge of ZIKV. Importantly, mice that survived did not show any signs of neurological disorder [70]. These three compounds inhibited the interaction between NS3 and the NS2B co-factor.

In addition to the compounds mentioned above, compound 22 (methylene blue (MB)) was found to significantly inhibit the NS2B and NS3 protease activity with 
IC 50 values in micromolar range via a non-competitive mechanism [71]. In addition, it was shown that compound 22 significantly reduced titres of multiple strains of ZIKV and DENV-2 with low micromolar and nanomolar EC 50 in cell-based antiviral assays. Moreover, compound 22 was found to inhibit viral replication in primary cells relevant to ZIKV pathogenesis and protect 3D mini-brain organoids from ZIKV infection. Animal model study confirmed that compound 22 treatment significantly increased the survival rate of mice challenged by a lethal dose of ZIKV [71].

Furthermore, compound 23 (erythrosin B (EB)) was found as a potent orthosteric inhibitor of the NS2B-NS3 proteases of ZIKV and DENV-2 with IC 50 values of $1.7 \mu \mathrm{M}$ and $1.9 \mu \mathrm{M}$, and EC 50 values of $0.62 \mu \mathrm{M}$ and $1.2 \mu \mathrm{M}$, respectively [72]. SAR studies suggested that compound 23 derivative compound 24 (JMX0902, or Acid Red 94) was slightly more potent than the compound 23 in inhibition of ZIKV replication, with an IC $_{50}$ of $2.6 \mu$ Mand $\mathrm{EC}_{50}$ of $0.3 \mu \mathrm{M}$ [73]. The SAR studies indicated that iodine substitutions at $\mathrm{R}_{1}$ and $\mathrm{R}_{3}$ positions of the xanthene ring were essential for compound 23's biological activities, whereas chlorine substitutions were allowed on the isobenzofuran ring of compound 23 [73].

Recently, a small library of niclosamide derivatives was screened, leading to identification of a new analogue with improved pharmacokinetic properties. The compound 25 (JMX0207) showed improved efficacy in inhibition of the molecular interaction between NS3 and NS2B, better inhibition of viral protease function at EC 50 of $0.3 \mu \mathrm{M}$ against DENV2 and $\mathrm{EC}_{50}$ of $0.31 \mu \mathrm{M}$ against ZIKV NS2B-NS3 interaction [74]. This compound also reduced ZIKV infection in 3D mini brain organoid and significantly reduced viremia in a ZIKV animal model [74].

In another study, Li et al developed an SLC-based conformational switch assay [15]. This assay monitors the conformational changes of NS2B after binding of inhibitor specific for NS2B-NS3 protease complex. Our aim was to identify and characterize allosteric inhibitors that prevent the formation of active conformation by NS2B [15]. From a virtual screening pipeline, twenty-nine compounds were selected for testing in a protease inhibition assay. One of these compounds, namely 26 (NSC135618), significantly inhibited the DENV-2 protease in vitro, with $\mathrm{IC}_{50}$ values of $1.8 \mu \mathrm{M}$. Compound $\mathbf{2 6}$ could also inhibit the protease conformational change in the SLC-based assay. Later it was found that compound 26 also inhibited viral replication of DENV, ZIKV, WNV, and YFV with EC 50 values in low micromolar range [15].

In a screening of 1,200 synthesized compounds targeting histone modifying enzymes including lysine specific demethylase1 (LSD1), Yao et al found compounds 2,3bis(4-bromophenyl)-5-(piperidin-4-ylmethoxy) pyrazine 27 and 2,3-bis(4(tert-butyl) phenyl)-5-(piperidin-4-ylmethoxy) pyrazine 28 as novel inhibitors with $\mathrm{IC}_{50}$ of 21.7 and $3.1 \mu \mathrm{M}$ against the ZIKV protease [75]. Through further SAR studies, a series of 2,5,6-trisubstituted pyrazine compounds are discovered as broadly active inhibitors of flavivirus proteases. Among them, compounds 29 with a furan-3-yl group and 30 with a tetrahydropyran-3-yl ring exhibited IC 50 values of $200 \mathrm{nM}$ and $130 \mathrm{nM}$, respectively, against the ZIKV protease and potently inhibited ZIKV replication with EC68 values of 300-600 nM [75]. In addition, Xray studies reveal that compound 29 binds to an allosteric pocket of NS3, providing a druggable pocket of the flavivirus protease, as contrasted to the shallow active site recognizing polar and positively charged Arg or Lys of the substrate [75]. Further studies confirmed that treatment with compound 29 at dose of $30 \mathrm{mg} / \mathrm{kg}$ for 3 days inhibited ZIKV viral loads in plasma and brain by up to 96 and $98 \%$ (at $24 \mathrm{~h}$ ), respectively [75,76]. Compound 29 also prolonged the mice survival rate.

Hybrid pharmacophores generated by combination of two individual pharmacophores with 1,2-Benzisothiazol-3(2H)-one (BIT) as the skeleton have been proven to show synergistic effects in inhibition of the DENV-2 NS2B-NS3 [77]. It was observed that BITs bind to the protease in vicinity of the catalytic triad. The BITs containing aromatic 
substitutions at the N-atom like compounds 31 with 2-methyl-4-nitrophenyl, 32 with 2chlorophenyl, and 33 2,6-dichlorophenyl showed the highest protease inhibition with $\mathrm{IC}_{50}$ of $2.56 \pm 1.03 \mu \mathrm{M}, 2.01 \pm 0.98 \mu \mathrm{M}$ and $5.28 \pm 1.89 \mu \mathrm{M}$, respectively. The DENV-2 infection assay showed that two BITs, the compound 32 reduced viral infectivity by 1.4 orders of magnitude and the compound 33 reduce the viral infectivity by about six fold [77].

Impermeability of the competitive inhibitors led the researchers to look for non-competitive inhibitors having better properties in terms of affinity, hydrophilicity, and lipophilic ligand efficiency. Millies et al developed a series of proline-based enantiomers of previously identified non-competitive inhibitors by exchange of the aromatic ether moiety to the 1-tosylprolinyl fragment [78]. The substitution pattern of the (sulfone) amide moiety was also judged for their effect on activity of the zika virus protease. The most potent inhibitor was the 4-nitrophenyl substituted sulfonamide $(R)-34$ with $I_{50}$ value of $0.32 \mu \mathrm{M}$. Further replacing the proline moiety with a pipecolinic acid afforded compounds $(R)-35$ and (S)-35 with IC 50 value of 0.51 and $0.58 \mu \mathrm{M}$, respectively [78]. Unfortunately, only compound $(R)-34$ showed moderate to weak antiviral efficacy against DENV and ZIKV.

\section{Conclusion and future direction}

This review reports the inhibitors of flavivirus NS2B-NS3 inhibitors evaluated in the last six years. Selected studies investigated the competitive and non-competitive inhibitors having the ability to block the activity of these proteases. Potential inhibitors were further investigated for antiviral activity against DENV, ZIKV and WNV. However, pharmacokinetic characteristics of majority of these compounds have not been reported, except for a few. One of the main barriers in the development of antiviral agents is the optimization of their absorption, distribution, metabolism, and excretion properties. Moreover, the flavivirus NS2B-NS3 protease is a serine protease similar to other host serine proteases. Therefore, inhibitors targeting the $\mathrm{P}$ side of protease could likely affect the activities important for host physiology. Inhibitors targeting the $\mathrm{P}^{\prime}$ side of the protease or its allosteric and orthosteric sites may be better options to counter the flavivirus infection in human individuals. Furthermore, effective compounds found in vitro study using the NS2B-NS3 protease assay should not solely be used in determining the pharmaceutical potential of compounds. Thus, extensive studies are needed to determine the in vivo performance of selected inhibitors against flavivirus infections.

Author Contributions: For research articles with several authors, a short paragraph specifying their individual contributions must be provided. The following statements should be used "Conceptualization, X.X. and Y.Y.; methodology, X.X.; software, X.X.; validation, X.X., Y.Y. and Z.Z.; formal analysis, X.X.; investigation, X.X.; resources, X.X.; data curation, X.X.; writing-original draft preparation, X.X.; writing - review and editing, X.X.; visualization, X.X.; supervision, X.X.; project administration, X.X.; funding acquisition, Y.Y. All authors have read and agreed to the published version of the manuscript." Please turn to the CRediT taxonomy for the term explanation. Authorship must be limited to those who have contributed substantially to the work reported.

Funding: Please add: "This research received no external funding" or "This research was funded by NAME OF FUNDER, grant number XXX" and "The APC was funded by XXX". Check carefully that the details given are accurate and use the standard spelling of funding agency names at https://search.crossref.org/funding. Any errors may affect your future funding.

Institutional Review Board Statement: In this section, you should add the Institutional Review Board Statement and approval number, if relevant to your study. You might choose to exclude this statement if the study did not require ethical approval. Please note that the Editorial Office might ask you for further information. Please add "The study was conducted in accordance with the Declaration of Helsinki, and approved by the Institutional Review Board (or Ethics Committee) of NAME OF INSTITUTE (protocol code XXX and date of approval)." for studies involving humans. OR "The animal study protocol was approved by the Institutional Review Board (or Ethics Committee) of NAME OF INSTITUTE (protocol code XXX and date of approval)." for studies involving animals. OR "Ethical review and approval were waived for this study due to REASON (please provide a detailed justification)." OR “Not applicable” for studies not involving humans or animals. 
Informed Consent Statement: Any research article describing a study involving humans should contain this statement. Please add "Informed consent was obtained from all subjects involved in the study." OR "Patient consent was waived due to REASON (please provide a detailed justification)." OR "Not applicable." for studies not involving humans. You might also choose to exclude this statement if the study did not involve humans. Written informed consent for publication must be obtained from participating patients who can be identified (including by the patients themselves). Please state "Written informed consent has been obtained from the patient(s) to publish this paper" if applicable.

Data Availability Statement: In this section, please provide details regarding where data supporting reported results can be found, including links to publicly archived datasets analyzed or generated during the study. Please refer to suggested Data Availability Statements in section "MDPI Research Data Policies" at https://www.mdpi.com/ethics. You might choose to exclude this statement if the study did not report any data.

Acknowledgments: This work was partially supported by grants AI161845, AI131669, AI140726, and AI141178 from the National Institute of Allergy and Infectious Diseases (NIAID), the National Institutes of Health (HL and JZ). Additionally, JZ is partly supported by John D. Stobo, the M.D. Distinguished Chair Endowment Fund at UTMB. HL is additionally supported by NIH grants AI133219, AI134568, AI140406, and AI140491, by University of Arizona College of Pharmacy faculty startup fund, and by R. Ken and Donna Coit Endowed Chair fund in Drug Discovery.

Conflicts of Interest: The authors declare no conflict of interest

\section{References}

1. Pierson, T.C.; Diamond, M.S. The continued threat of emerging flaviviruses. Nature Microbiology 2020, 5, 796-812, doi:10.1038/s41564-020-0714-0.

2. Best, S.M. Flaviviruses. Curr Biol 2016, 26, R1258-r1260, doi:10.1016/j.cub.2016.09.029.

3. Li, Z.; Zhang, J.; Li, H. Flavivirus NS2B/NS3 Protease: Structure, Function, and Inhibition. In Viral Proteases and Their Inhibitors; 2017; pp. 163-188.

4. Brecher, M.; Zhang, J.; Li, H. The flavivirus protease as a target for drug discovery. Virol Sin 2013, 28, 326-336, doi:10.1007/s12250013-3390-x.

5. Kayesh, M.E.H.; Tsukiyama-Kohara, K. Mammalian animal models for dengue virus infection: a recent overview. Archives of Virology 2021, doi:10.1007/s00705-021-05298-2.

6. Bhatt, S.; Gething, P.W.; Brady, O.J.; Messina, J.P.; Farlow, A.W.; Moyes, C.L.; Drake, J.M.; Brownstein, J.S.; Hoen, A.G.; Sankoh, O; et al. The global distribution and burden of dengue. Nature 2013, 496, 504-507, doi:10.1038/nature12060.

7. Gubler, D.J. Dengue/dengue haemorrhagic fever: history and current status. Novartis Found Symp 2006, 277, 3-16; discussion 1622, 71-13, 251-253, doi:10.1002/0470058005.ch2.

8. Pfeffer, M.; Dobler, G. Emergence of zoonotic arboviruses by animal trade and migration. Parasites $\mathcal{E}$ Vectors 2010, 3, 35, doi:10.1186/1756-3305-3-35.

9. Pierson, T.C.; Diamond, M.S. The continued threat of emerging flaviviruses. Nat Microbiol 2020, 5, 796-812, doi:10.1038/s41564020-0714-0.

10. Enserink, M. INFECTIOUS DISEASES. An obscure mosquito-borne disease goes global. Science 2015, 350, 1012-1013, doi:10.1126/science.350.6264.1012.

11. Holbrook, M. Historical Perspectives on Flavivirus Research. Viruses 2017, 9, 97, doi:10.3390/v9050097.

12. Mackenzie, J.S.; Gubler, D.J.; Petersen, L.R. Emerging flaviviruses: the spread and resurgence of Japanese encephalitis, West Nile and dengue viruses. Nature Medicine 2004, 10, S98-S109, doi:10.1038/nm1144.

13. Roehrig, J. West Nile Virus in the United States - A Historical Perspective. Viruses 2013, 5, 3088-3108, doi:10.3390/v5123088.

14. Pierson, T.C.; Diamond, M.S. The emergence of Zika virus and its new clinical syndromes. Nature 2018, 560, 573-581, doi:10.1038/s41586-018-0446-y.

15. Brecher, M.; Li, Z.; Liu, B.; Zhang, J.; Koetzner, C.A.; Alifarag, A.; Jones, S.A.; Lin, Q.; Kramer, L.D.; Li, H. A conformational switch high-throughput screening assay and allosteric inhibition of the flavivirus NS2B-NS3 protease. PLoS Pathog 2017, 13, e1006411, doi:10.1371/journal.ppat.1006411.

16. Solomon, T.; Mallewa, M. Dengue and other emerging flaviviruses. J Infect 2001, 42, 104-115, doi:10.1053/jinf.2001.0802.

17. Norshidah, H.; Vignesh, R.; Lai, N.S. Updates on Dengue Vaccine and Antiviral: Where Are We Heading? Molecules 2021, 26, doi:10.3390/molecules26226768.

18. Meganck, R.M.; Baric, R.S. Developing therapeutic approaches for twenty-first-century emerging infectious viral diseases. Nature Medicine 2021, 27, 401-410, doi:10.1038/s41591-021-01282-0.

19. Zhao, R.; Wang, M.; Cao, J.; Shen, J.; Zhou, X.; Wang, D.; Cao, J. Flavivirus: From Structure to Therapeutics Development. Life 2021, 11, 615, doi:10.3390/life11070615. 
20. Gebhard, L.G.; Filomatori, C.V.; Gamarnik, A.V. Functional RNA Elements in the Dengue Virus Genome. Viruses 2011, 3, 17391756, doi:10.3390/v3091739.

21. Zhang, X.; Zhang, Y.; Jia, R.; Wang, M.; Yin, Z.; Cheng, A. Structure and function of capsid protein in flavivirus infection and its applications in the development of vaccines and therapeutics. Veterinary Research 2021, 52, doi:10.1186/s13567-021-00966-2.

22. Obi, J.O.; Gutiérrez-Barbosa, H.; Chua, J.V.; Deredge, D.J. 2021, doi:10.20944/preprints202108.0364.v1.

23. Bollati, M.; Alvarez, K.; Assenberg, R.; Baronti, C.; Canard, B.; Cook, S.; Coutard, B.; Decroly, E.; de Lamballerie, X.; Gould, E.A.; et al. Structure and functionality in flavivirus NS-proteins: perspectives for drug design. Antiviral Res 2010, 87, 125-148, doi:10.1016/j.antiviral.2009.11.009.

24. Natarajan, S. NS3 protease from flavivirus as a target for designing antiviral inhibitors against dengue virus. Genetics and Molecular Biology 2010, 33, 214-219, doi:10.1590/s1415-47572010000200002.

25. Assenberg, R.; Mastrangelo, E.; Walter, T.S.; Verma, A.; Milani, M.; Owens, R.J.; Stuart, D.I.; Grimes, J.M.; Mancini, E.J. Crystal structure of a novel conformational state of the flavivirus NS3 protein: implications for polyprotein processing and viral replication. J Virol 2009, 83, 12895-12906, doi:10.1128/jvi.00942-09.

26. Shi, P.Y.; Kauffman, E.B.; Ren, P.; Felton, A.; Tai, J.H.; Dupuis, A.P., 2nd; Jones, S.A.; Ngo, K.A.; Nicholas, D.C.; Maffei, J.; et al. High-throughput detection of West Nile virus RNA. J Clin Microbiol 2001, 39, 1264-1271, doi:10.1128/JCM.39.4.1264-1271.2001.

27. Falgout, B.; Pethel, M.; Zhang, Y.M.; Lai, C.J. Both nonstructural proteins NS2B and NS3 are required for the proteolytic processing of dengue virus nonstructural proteins. J Virol 1991, 65, 2467-2475, doi:10.1128/jvi.65.5.2467-2475.1991.

28. Cahour, A.; Falgout, B.; Lai, C.J. Cleavage of the dengue virus polyprotein at the NS3/NS4A and NS4B/NS5 junctions is mediated by viral protease NS2B-NS3, whereas NS4A/NS4B may be processed by a cellular protease. J Virol 1992, 66, 1535-1542, doi:10.1128/jvi.66.3.1535-1542.1992.

29. Jan, L.R.; Yang, C.S.; Trent, D.W.; Falgout, B.; Lai, C.J. Processing of Japanese encephalitis virus non-structural proteins: NS2BNS3 complex and heterologous proteases. J Gen Virol 1995, 76 ( Pt 3), 573-580, doi:10.1099/0022-1317-76-3-573.

30. Benarroch, D.; Selisko, B.; Locatelli, G.A.; Maga, G.; Romette, J.L.; Canard, B. The RNA helicase, nucleotide 5'-triphosphatase, and RNA 5'-triphosphatase activities of Dengue virus protein NS3 are Mg2+-dependent and require a functional Walker B motif in the helicase catalytic core. Virology 2004, 328, 208-218, doi:10.1016/j.virol.2004.07.004.

31. Van Den Elsen, K.; Quek, J.P.; Luo, D. Molecular Insights into the Flavivirus Replication Complex. Viruses 2021, 13, 956, doi:10.3390/v13060956.

32. Clum, S.; Ebner, K.E.; Padmanabhan, R. Cotranslational Membrane Insertion of the Serine Proteinase Precursor NS2B-NS3(Pro) of Dengue Virus Type 2 Is Required for Efficient in Vitro Processing and Is Mediated through the Hydrophobic Regions of NS2B. Journal of Biological Chemistry 1997, 272, 30715-30723, doi:10.1074/jbc.272.49.30715.

33. Xu, T.; Sampath, A.; Chao, A.; Wen, D.; Nanao, M.; Chene, P.; Vasudevan, S.G.; Lescar, J. Structure of the Dengue Virus Helicase/Nucleoside Triphosphatase Catalytic Domain at a Resolution of 2.4 A. Journal of Virology 2005, 79, 10278-10288, doi:10.1128/jvi.79.16.10278-10288.2005.

34. Lescar, J.; Luo, D.; Xu, T.; Sampath, A.; Lim, S.P.; Canard, B.; Vasudevan, S.G. Towards the design of antiviral inhibitors against flaviviruses: the case for the multifunctional NS3 protein from Dengue virus as a target. Antiviral Res 2008, 80, 94-101, doi:10.1016/j.antiviral.2008.07.001.

35. Yamashita, T.; Unno, H.; Mori, Y.; Tani, H.; Moriishi, K.; Takamizawa, A.; Agoh, M.; Tsukihara, T.; Matsuura, Y. Crystal structure of the catalytic domain of Japanese encephalitis virus NS3 helicase/nucleoside triphosphatase at a resolution of 1.8 A. Virology 2008, 373, 426-436, doi:10.1016/j.virol.2007.12.018.

36. Kim, Y.M.; Gayen, S.; Kang, C.; Joy, J.; Huang, Q.; Chen, A.S.; Wee, J.L.; Ang, M.J.; Lim, H.A.; Hung, A.W.; et al. NMR analysis of a novel enzymatically active unlinked dengue NS2B-NS3 protease complex. J Biol Chem 2013, 288, 12891-12900, doi:10.1074/jbc.M112.442723.

37. Shannon, A.E.; Chappell, K.J.; Stoermer, M.J.; Chow, S.Y.; Kok, W.M.; Fairlie, D.P.; Young, P.R. Simultaneous uncoupled expression and purification of the Dengue virus NS3 protease and NS2B co-factor domain. Protein Expr Purif 2016, 119, 124-129, doi:10.1016/j.pep.2015.11.022.

38. Phong, W.Y.; Moreland, N.J.; Lim, S.P.; Wen, D.; Paradkar, P.N.; Vasudevan, S.G. Dengue protease activity: the structural integrity and interaction of NS2B with NS3 protease and its potential as a drug target. Biosci Rep 2011, 31, 399-409, doi:10.1042/bsr20100142.

39. Hilgenfeld, R.; Lei, J.; Zhang, L. The Structure of the Zika Virus Protease, NS2B/NS3(pro). Adv Exp Med Biol 2018, 1062, 131-145, doi:10.1007/978-981-10-8727-1_10.

40. Wu, C.F.; Wang, S.H.; Sun, C.M.; Hu, S.T.; Syu, W.J. Activation of dengue protease autocleavage at the NS2B-NS3 junction by recombinant NS3 and GST-NS2B fusion proteins. J Virol Methods 2003, 114, 45-54, doi:10.1016/j.jviromet.2003.09.001.

41. Felicetti, T.; Manfroni, G.; Cecchetti, V.; Cannalire, R. Broad-Spectrum Flavivirus Inhibitors: a Medicinal Chemistry Point of View. ChemMedChem 2020, 15, 2391-2419, doi:10.1002/cmdc.202000464.

42. Wensing, A.M.; van Maarseveen, N.M.; Nijhuis, M. Fifteen years of HIV Protease Inhibitors: raising the barrier to resistance. Antiviral Res 2010, 85, 59-74, doi:10.1016/j.antiviral.2009.10.003.

43. Ghosh, A.K.; Osswald, H.L.; Prato, G. Recent Progress in the Development of HIV-1 Protease Inhibitors for the Treatment of HIV/AIDS. J Med Chem 2016, 59, 5172-5208, doi:10.1021/acs.jmedchem.5b01697.

44. Abdel-Rahman, H.M.; Al-karamany, G.S.; El-Koussi, N.A.; Youssef, A.F.; Kiso, Y. HIV protease inhibitors: peptidomimetic drugs and future perspectives. Curr Med Chem 2002, 9, 1905-1922, doi:10.2174/0929867023368890. 
45. Wyles, D.L. Antiviral Resistance and the Future Landscape of Hepatitis C Virus Infection Therapy. The Journal of Infectious Diseases 2013, 207, S33-S39, doi:10.1093/infdis/jis761.

46. Zhang, X. Direct anti-HCV agents. Acta Pharm Sin B 2016, 6, 26-31, doi:10.1016/j.apsb.2015.09.008.

47. Meewan, I.; Zhang, X.; Roy, S.; Ballatore, C.; O’Donoghue, A.J.; Schooley, R.T.; Abagyan, R. Discovery of New Inhibitors of Hepatitis C Virus NS3/4A Protease and Its D168A Mutant. ACS Omega 2019, 4, 16999-17008, doi:10.1021/acsomega.9b02491.

48. Ali, A.; Aydin, C.; Gildemeister, R.; Romano, K.P.; Cao, H.; Ozen, A.; Soumana, D.; Newton, A.; Petropoulos, C.J.; Huang, W.; et al. Evaluating the role of macrocycles in the susceptibility of hepatitis $C$ virus NS3/4A protease inhibitors to drug resistance. ACS Chem Biol 2013, 8, 1469-1478, doi:10.1021/cb400100g.

49. Choksupmanee, O.; Hodge, K.; Katzenmeier, G.; Chimnaronk, S. Structural Platform for the Autolytic Activity of an Intact NS2B-NS3 Protease Complex from Dengue Virus. Biochemistry 2012, 51, 2840-2851, doi:10.1021/bi2018267.

50. Huang, Q.; Li, Q.; Joy, J.; Chen, A.S.; Ruiz-Carrillo, D.; Hill, J.; Lescar, J.; Kang, C. Lyso-myristoyl phosphatidylcholine micelles sustain the activity of Dengue non-structural (NS) protein 3 protease domain fused with the full-length NS2B. Protein Expr Purif 2013, 92, 156-162, doi:10.1016/j.pep.2013.09.015.

51. Erbel, P.; Schiering, N.; D'Arcy, A.; Renatus, M.; Kroemer, M.; Lim, S.P.; Yin, Z.; Keller, T.H.; Vasudevan, S.G.; Hommel, U. Structural basis for the activation of flaviviral NS3 proteases from dengue and West Nile virus. Nat Struct Mol Biol 2006, 13, 372373, doi:10.1038/nsmb1073.

52. Noble, C.G.; Seh, C.C.; Chao, A.T.; Shi, P.Y. Ligand-Bound Structures of the Dengue Virus Protease Reveal the Active Conformation. Journal of Virology 2012, 86, 438-446, doi:10.1128/jvi.06225-11.

53. Hale, B.G.; Randall, R.E.; Ortín, J.; Jackson, D. The multifunctional NS1 protein of influenza A viruses. J Gen Virol 2008, 89, 23592376, doi:10.1099/vir.0.2008/004606-0.

54. Niyomrattanakit, P.; Winoyanuwattikun, P.; Chanprapaph, S.; Angsuthanasombat, C.; Panyim, S.; Katzenmeier, G. Identification of residues in the dengue virus type 2 NS2B cofactor that are critical for NS3 protease activation. J Virol 2004, 78, 13708-13716, doi:10.1128/jvi.78.24.13708-13716.2004.

55. Yuan, S.; Chan, J.F.; den-Haan, H.; Chik, K.K.; Zhang, A.J.; Chan, C.C.; Poon, V.K.; Yip, C.C.; Mak, W.W.; Zhu, Z.; et al. Structurebased discovery of clinically approved drugs as Zika virus NS2B-NS3 protease inhibitors that potently inhibit Zika virus infection in vitro and in vivo. Antiviral Res 2017, 145, 33-43, doi:10.1016/j.antiviral.2017.07.007.

56. Pathak, N.; Lai, M.L.; Chen, W.Y.; Hsieh, B.W.; Yu, G.Y.; Yang, J.M. Pharmacophore anchor models of flaviviral NS3 proteases lead to drug repurposing for DENV infection. BMC Bioinformatics 2017, 18, 548, doi:10.1186/s12859-017-1957-5.

57. Rassias, G.; Zogali, V.; Swarbrick, C.M.D.; Ki Chan, K.W.; Chan, S.A.; Gwee, C.P.; Wang, S.; Kaplanai, E.; Canko, A.; Kiousis, D.; et al. Cell-active carbazole derivatives as inhibitors of the zika virus protease. Eur J Med Chem 2019, 180, 536-545, doi:10.1016/j.ejmech.2019.07.007.

58. Abrams, R.P.M.; Yasgar, A.; Teramoto, T.; Lee, M.H.; Dorjsuren, D.; Eastman, R.T.; Malik, N.; Zakharov, A.V.; Li, W.; Bachani, M.; et al. Therapeutic candidates for the Zika virus identified by a high-throughput screen for Zika protease inhibitors. Proc Natl Acad Sci U S A 2020, 117, 31365-31375, doi:10.1073/pnas.2005463117.

59. Akaberi, D.; Chinthakindi, P.K.; Båhlström, A.; Palanisamy, N.; Sandström, A.; Lundkvist, Å.; Lennerstrand, J. Identification of a C2-symmetric diol based human immunodeficiency virus protease inhibitor targeting Zika virus NS2B-NS3 protease. J Biomol Struct Dyn 2020, 38, 5526-5536, doi:10.1080/07391102.2019.1704882.

60. Akaberi, D.; Båhlström, A.; Chinthakindi, P.K.; Nyman, T.; Sandström, A.; Järhult, J.D.; Palanisamy, N.; Lundkvist, Å.; Lennerstrand, J. Targeting the NS2B-NS3 protease of tick-borne encephalitis virus with pan-flaviviral protease inhibitors. Antiviral Res 2021, 190, 105074, doi:10.1016/j.antiviral.2021.105074.

61. Behnam, M.A.; Graf, D.; Bartenschlager, R.; Zlotos, D.P.; Klein, C.D. Discovery of Nanomolar Dengue and West Nile Virus Protease Inhibitors Containing a 4-Benzyloxyphenylglycine Residue. J Med Chem 2015, 58, 9354-9370, doi:10.1021/acs.jmedchem.5b01441.

62. Wu, D.W.; Mao, F.; Ye, Y.; Li, J.; Xu, C.L.; Luo, X.M.; Chen, J.; Shen, X. Policresulen, a novel NS2B/NS3 protease inhibitor, effectively inhibits the replication of DENV2 virus in BHK-21 cells. Acta Pharmacol Sin 2015, 36, 1126-1136, doi:10.1038/aps.2015.56.

63. Takagi, Y.; Matsui, K.; Nobori, H.; Maeda, H.; Sato, A.; Kurosu, T.; Orba, Y.; Sawa, H.; Hattori, K.; Higashino, K.; et al. Discovery of novel cyclic peptide inhibitors of dengue virus NS2B-NS3 protease with antiviral activity. Bioorg Med Chem Lett 2017, 27, 3586-3590, doi:10.1016/j.bmcl.2017.05.027.

64. Mueller, N.H.; Yon, C.; Ganesh, V.K.; Padmanabhan, R. Characterization of the West Nile virus protease substrate specificity and inhibitors. Int J Biochem Cell Biol 2007, 39, 606-614, doi:10.1016/j.biocel.2006.10.025.

65. Lin, K.H.; Ali, A.; Rusere, L.; Soumana, D.I.; Kurt Yilmaz, N.; Schiffer, C.A. Dengue Virus NS2B/NS3 Protease Inhibitors Exploiting the Prime Side. J Virol 2017, 91, doi:10.1128/JVI.00045-17.

66. Cabarcas-Montalvo, M.; Maldonado-Rojas, W.; Montes-Grajales, D.; Bertel-Sevilla, A.; Wagner-Döbler, I.; Sztajer, H.; Reck, M.; Flechas-Alarcon, M.; Ocazionez, R.; Olivero-Verbel, J. Discovery of antiviral molecules for dengue: In silico search and biological evaluation. Eur J Med Chem 2016, 110, 87-97, doi:10.1016/j.ejmech.2015.12.030.

67. Bastos Lima, A.; Behnam, M.A.; El Sherif, Y.; Nitsche, C.; Vechi, S.M.; Klein, C.D. Dual inhibitors of the dengue and West Nile virus NS2B-NS3 proteases: Synthesis, biological evaluation and docking studies of novel peptide-hybrids. Bioorg Med Chem 2015, 23, 5748-5755, doi:10.1016/j.bmc.2015.07.012. 
68. Skoreński, M.; Milewska, A.; Pyrć, K.; Sieńczyk, M.; Oleksyszyn, J. Phosphonate inhibitors of West Nile virus NS2B/NS3 protease. Journal of Enzyme Inhibition and Medicinal Chemistry 2019, 34, 8-14, doi:10.1080/14756366.2018.1506772.

69. Cui, X.; Zhou, R.; Huang, C.; Zhang, R.; Wang, J.; Zhang, Y.; Ding, J.; Li, X.; Zhou, J.; Cen, S. Identification of Theaflavin-3,3'Digallate as a Novel Zika Virus Protease Inhibitor. Frontiers in Pharmacology 2020, 11, doi:10.3389/fphar.2020.514313.

70. Li, Z.; Brecher, M.; Deng, Y.Q.; Zhang, J.; Sakamuru, S.; Liu, B.; Huang, R.; Koetzner, C.A.; Allen, C.A.; Jones, S.A.; et al. Existing drugs as broad-spectrum and potent inhibitors for Zika virus by targeting NS2B-NS3 interaction. Cell Res 2017, 27, 1046-1064, doi:10.1038/cr.2017.88.

71. Li, Z.; Lang, Y.; Sakamuru, S.; Samrat, S.; Trudeau, N.; Kuo, L.; Rugenstein, N.; Tharappel, A.; D'Brant, L.; Koetzner, C.A.; et al. Methylene blue is a potent and broad-spectrum inhibitor against Zika virus in vitro and in vivo. Emerg Microbes Infect 2020, 9, 2404-2416, doi:10.1080/22221751.2020.1838954.

72. Li, Z.; Sakamuru, S.; Huang, R.; Brecher, M.; Koetzner, C.A.; Zhang, J.; Chen, H.; Qin, C.F.; Zhang, Q.Y.; Zhou, J.; et al. Erythrosin $\mathrm{B}$ is a potent and broad-spectrum orthosteric inhibitor of the flavivirus NS2B-NS3 protease. Antiviral Res 2018, 150, 217-225, doi:10.1016/j.antiviral.2017.12.018.

73. Li, Z.; Xu, J.; Lang, Y.; Wu, X.; Hu, S.; Samrat, S.; Tharappel, A.; Kuo, L.; Butler, D.; Song, Y.; et al. In vitro and in vivo characterization of erythrosin $\mathrm{B}$ and derivatives against Zika virus. Acta Pharmaceutica Sinica B 2021, doi:10.1016/j.apsb.2021.10.017.

74. Li, Z.; Xu, J.; Lang, Y.; Fan, X.; Kuo, L.; D’Brant, L.; Hu, S.; Samrat, S.K.; Trudeau, N.; Tharappel, A.M.; et al. JMX0207, a Niclosamide Derivative with Improved Pharmacokinetics, Suppresses Zika Virus Infection Both In Vitro and In Vivo. ACS Infectious Diseases 2020, 6, 2616-2628, doi:10.1021/acsinfecdis.0c00217.

75. Yao, Y.; Huo, T.; Lin, Y.L.; Nie, S.; Wu, F.; Hua, Y.; Wu, J.; Kneubehl, A.R.; Vogt, M.B.; Rico-Hesse, R.; et al. Discovery, X-ray Crystallography and Antiviral Activity of Allosteric Inhibitors of Flavivirus NS2B-NS3 Protease. J Am Chem Soc 2019, 141, 68326836, doi:10.1021/jacs.9b02505.

76. Nie, S.; Yao, Y.; Wu, F.; Wu, X.; Zhao, J.; Hua, Y.; Wu, J.; Huo, T.; Lin, Y.L.; Kneubehl, A.R.; et al. Synthesis, Structure-Activity Relationships, and Antiviral Activity of Allosteric Inhibitors of Flavivirus NS2B-NS3 Protease. J Med Chem 2021, 64, 2777-2800, doi:10.1021/acs.jmedchem.0c02070.

77. Batool, F.; Saeed, M.; Saleem, H.N.; Kirschner, L.; Bodem, J. Facile Synthesis and In Vitro Activity of N-Substituted 1,2Benzisothiazol-3(2H)-ones against Dengue Virus NS2BNS3 Protease. Pathogens 2021, 10, doi:10.3390/pathogens10040464.

78. Millies, B.; von Hammerstein, F.; Gellert, A.; Hammerschmidt, S.; Barthels, F.; Göppel, U.; Immerheiser, M.; Elgner, F.; Jung, N.; Basic, M.; et al. Proline-Based Allosteric Inhibitors of Zika and Dengue Virus NS2B/NS3 Proteases. J Med Chem 2019, 62, 1135911382, doi:10.1021/acs.jmedchem.9b01697. 